\title{
Overweight May Have Some Positive Reproductive Benefits as Compared to Obese Represented by Higher Sperm Progressive Motility in Infertile Men
}

\author{
Inari MI Ciccone ${ }^{1,2}$, Juliana R Pariz ${ }^{1,2,3,6}$, Ivan Iori ${ }^{1}$, Giovanna Milani ${ }^{1}$, Gustavo De Aguiar Andrade ${ }^{1}$, Elaine \\ Frade Costa ${ }^{1,3,4,5}$ and Jorge Hallak*1,2,3,6
}

${ }^{1}$ Androscience - Science and Innovation Center and High Complexity Clinical and Research Andrology Laboratory, Brazil

${ }^{2}$ Division of Urology, Brazil

${ }^{3}$ Men's Health Study Group, Institute for Advanced Studies, Brazil

${ }^{4}$ School of Medicine, Brazil

${ }^{5}$ Division of Endocrinology, Brazil

${ }^{6}$ Reproductive Toxicology Unit, Department of Pathology, Brazil

*Corresponding author: Jorge Hallak, Androscience-High Complexity Clinical and Research Andrology Laboratory, Brazil.
Received Date: May 01, 2019

Published Date: June 17, 2019

\begin{abstract}
Objective: The purpose of this study is to unfold the relationship between overweight, sperm parameters and hormonal levels in infertile men in the reproductive age.

Methods: From 2010 to 2013, 76 patients from Androscience, Science and Innovation Center and High-Complexity Andrology Laboratory aged 18 to 55 years were retrospectively analyzed. Semen analysis results were correlated with Body Mass Index (BMI) in patients primarily evaluated for male infertility. According to nutritional status, patients were classified into three major groups, (I) normal range group (18.5 to $\left.24.99 \mathrm{~kg} / \mathrm{m}^{2}\right)$, (II) overweight group ( 25.0 to $29.99 \mathrm{~kg} / \mathrm{m}^{2}$ ) and (III) obesity group (over $30 \mathrm{~kg} / \mathrm{m}^{2}$ ). The relationship between semen quality and hormonal levels was evaluated in each group. Mean results were compared and adopted $\mathrm{p}>0.05$ as statistically significant.
\end{abstract}

Results: Overall, $56 \%$ of patients ( $\mathrm{n}=42$; mean 36.76 years-old) were classified as overweight, $26 \%$ normal BMI ( $\mathrm{n}=20$; mean 38.2 y.o.) and $18 \%$ ( $n=14$; mean 39.71 y.o.) of the patients were obese. Regarding seminal analysis, no significant difference in sperm concentration, total motility and normal sperm morphology were identified $(\mathrm{p}>0.05)$. However, total progressive motility was $14.54 \%$ higher in the overweight group in comparison with the obesity group $(\mathrm{p}=0.063)$.

Conclusion: The results indicated a relationship between overweight infertile men and an increase in progressive motility, further reinforcing the need for a global assessment of men's health, especially in certain subgroups of men such those who desire to father their own offspring currently or in the future.

\section{Introduction}

The obesity epidemic is being considered as a serious growing global public health issue. The prevalence of the disease has increased dramatically since 1980 , and in fact, over $60 \%$ of the North American population have overweight or obesity [1,2]. The World Health Organization (WHO) estimates that 1,6 billion adults have Body Mass Index (BMI) between 25 and $30 \mathrm{~kg} / \mathrm{m}^{2}$, classified as overweight, and 400 million have a BMI over $30 \mathrm{~kg} / \mathrm{m}^{2}$,

classified as obese [3]. The Brazilian population is not an exception to this global trend, since overweight affects over half the whole population, regardless of gender [4]. Obesity has been established as a leading direct or indirect cause of morbidity and mortality, driven by an increase in related life-threatening disorders, including dyslipidemia, hypertension, cancer, type 2 diabetes, metabolic disorders, reproductive and sexual health impairment [5]. Although both males and females are affected by this lifestyle disorder in 
the post-modern Era, there are still few studies addressing male reproductive health and fertility status [6].

Infertility is also a worldwide phenomenon as it affects around $15 \%$ of couples who seek to obtain a pregnancy, regardless of their cultural and social background after twelve months of unprotected, frequent sexual intercourse [7]. A gradual decrease in sperm quality, particularly sperm count, has been strongly suggested since the 1970s [8-11]. Although still controversy exists towards methodological standardization of the techniques, environmental factors such as air pollution, habits (tobacco, drugs, toxins, etc.), and aging are undoubtedly correlated to a decrease in semen quality. More studies are necessary to address the relationship of overweight and sperm quality as a few numbers of publications have already looked in the nutritional status [10,12-20]. The purpose of this study is to shed light into the relationship between overweight men, basic semen parameters and hormonal levels in infertile men in the reproductive age.

\section{Methods}

\section{Study population}

We have retrospectively looked our collected data, between 2010 and 2013 at Androscience - Clinical and Research Andrology Laboratory, of 76 patients aged 18 to 55 years, with BMI evaluation, seminal analysis, levels of male sex hormones who presented with diagnosis of male infertility. This study was approved by the Research Ethics Committee of Hospital das Clinicas, Faculty of Medicine, University of São Paulo (1007/07) and all volunteers signed an Informed Consent Form. The data survey was conducted after an un-identification of medical records to set up the database. It considered the patients confidentiality. Exclusion criteria included: patient's records information missing, with azoospermia or whose did not meet the above-mentioned conditions.

\section{Body mass index (BMI)}

The BMI was obtained dividing the weight $(\mathrm{kg})$ by the square of height in meters (m). Specifically, all patients were weighted using the digital self-calibrating Marte scale, after removing shoes and excessive clothes. Height was measured using a Charder estadiometer, without shoes and following all precision protocol according to Guide to Physical Measurements (Step 2) World Health Organization (WHO) in 2008 [21]. The BMI classification by WHO criteria was used for nutritional diagnosis and then, patients were divided into 4 groups such as underweight group $(\otimes 18.5 \mathrm{~kg} /$ $\mathrm{m}^{2}$ ), normal rage group (18.5 to $24.99 \mathrm{~kg} / \mathrm{m}^{2}$ ), overweight group (25.0 to $29.99 \mathrm{~kg} / \mathrm{m}^{2}$ ) and obesity group (over $30 \mathrm{~kg} / \mathrm{m}^{2}$ ).

\section{Semen analysis}

Semen specimens were collected after 48 to 72 hours of sexual abstinence by masturbation into a sterile plastic container and all semen parameters were tested within one hour after ejaculation at $37^{\circ} \mathrm{C}$. After liquefaction, all semen analysis was performed manually. Macroscopic and microscopic parameters were performed according to WHO guidelines (2010) [22]. The following variables were determinate: sperm concentration (million/ml), total motility (progressive + no progressive sperm motility; \%), progressive motility (PR; \%) and strict morphology (\%). Sperm morphology was assessed using the methodology described by Kruger (1988) [23] and by WHO [22].

\section{Levels of male sex hormones}

The biochemical and hormonal tests were composed by the dosage of serum total testosterone $(\mathrm{ng} / \mathrm{dL})$, free testosterone (pmol/L), prolactin (mcg/L), serum follicle stimulating hormone (FSH $\mathrm{mlU} / \mathrm{ml}$ ), luteinizing hormone ( $\mathrm{LH} ; \mathrm{mlU} / \mathrm{ml}$ ) and estradiol (ng/dL). Patients were instructed previously to do not physical activity before collection to avoid stress and fatigue.

\section{Statistical analysis}

The tests were performed in SPSS 15.0 software and was adopted the significance level of $5 \%$. The BMI was described according to traditional classification with relative and absolutely frequency use. Underweight BMI patients were grouped in the healthy category and the obesity group was not considered, leaving only three BMI category. The seminal analysis and hormonal dosage data were tested according to the distribution normality with using Kolmogorov-Smirnov test. Only the morphology such a strict criterion provided normality escape on distribution; therefore, all variations were compared as BMI using ANOVA test. The correlations that Bonferroni compared reached statistical significance multiply test to check with BMI categories showed summarizing main differences. The strict criterion morphology was compared as BMI categories using Kruskal-Wallis test.

\section{Results}

Table 1: Nutritional Status according BMI evaluation on infertility patients.

\begin{tabular}{|c|c|c|}
\hline Group & N & Frequency \\
\hline Normal Range & 20 & $26.30 \%$ \\
\hline Overweight & 42 & $55.30 \%$ \\
\hline Obesity & 14 & $18.40 \%$ \\
\hline Total & 76 & $100.00 \%$ \\
\hline
\end{tabular}

Following the inclusion and exclusion criterions, 76 infertile patients were included. Overall, $56 \%$ of patients $(n=42$; mean age of 36.76 years-old) were classified as overweight, $26 \%$ ( $n=20$; mean age of 38.2 y.o.) had a normal BMI and $18 \%$ ( $n=14$; mean age of 39.71 y.o) were obese patients. Therefore $74 \%$ of the sample have an elevated body mass index (Table 1). In (Table 2), we can observe the percentage distribution of patients according to body mass index (BMI) and seminal diagnosis. The frequency of varicocele was $75 \%(n=15)$ in eutrophic, 64\% ( $=27)$ in overweight and $64 \%(n=9)$ in obese groups. Regarding seminal analysis, there was no significant difference of sperm concentration, total motility and normal sperm morphology between groups ( $p>0.05$ ) (Table 2 ). On the other hand, progressive motility was $14.54 \%$ higher in overweight group in comparison with obese group $(\mathrm{p}=0.044)$ (Table 3). In addition, no statistical differences were observed in total serum testosterone, free testosterone, prolactin, FSH, LH and estradiol levels ( $\mathrm{p}>0.05)$ (Table 4$)$. 
Table 2: Percentage distribution of patients according to body mass index (BMI), and breakdown according to two basic semen parameters: sperm count and motility.

\begin{tabular}{|c|c|c|c|c|}
\hline & \multicolumn{3}{|c|}{ Body mass index groups } & \multirow[t]{2}{*}{ Total } \\
\hline & $\begin{array}{c}\text { Normal } \\
\text { range }\end{array}$ & Overweight & Obese & \\
\hline \multicolumn{5}{|c|}{ Normozoospermic } \\
\hline $\mathrm{N}$ & 5 & 18 & 1 & 24 \\
\hline $\begin{array}{l}\% \text { within BMI } \\
\text { group }\end{array}$ & $25.00 \%$ & $42.90 \%$ & $7.10 \%$ & $31.60 \%$ \\
\hline$\%$ of total & $6.60 \%$ & $23.70 \%$ & $1.30 \%$ & $31.60 \%$ \\
\hline \multicolumn{5}{|c|}{ Astenozoospermia } \\
\hline $\mathrm{N}$ & 13 & 11 & 7 & 31 \\
\hline $\begin{array}{l}\% \text { within BMI } \\
\text { group }\end{array}$ & $65.00 \%$ & $26.20 \%$ & $50.00 \%$ & $40.80 \%$ \\
\hline$\%$ of total & $17.10 \%$ & $14.50 \%$ & $9.20 \%$ & $40.80 \%$ \\
\hline \multicolumn{5}{|c|}{ Oligozoospermia } \\
\hline $\mathrm{N}$ & 1 & 1 & 0 & 2 \\
\hline $\begin{array}{l}\% \text { within BMI } \\
\text { group }\end{array}$ & $5.00 \%$ & $2.40 \%$ & $0 \%$ & $2.60 \%$ \\
\hline$\%$ of total & $1.30 \%$ & $1.30 \%$ & $0 \%$ & $2.60 \%$ \\
\hline \multicolumn{5}{|c|}{ Oligoastenozoospermia } \\
\hline $\mathrm{N}$ & 1 & 12 & 6 & 19 \\
\hline $\begin{array}{l}\% \text { within BMI } \\
\text { group }\end{array}$ & $5.00 \%$ & $28.60 \%$ & $42.90 \%$ & $25.00 \%$ \\
\hline$\%$ of total & $1.30 \%$ & $1.30 \%$ & $7.90 \%$ & $25.00 \%$ \\
\hline
\end{tabular}

Table 3: Median, Standard deviation, maximum and minimum values of seminal parameters sperm concentration (million $/ \mathrm{mL}$ ), total motility (PR+NP; \%), progressive motility (PR; \%), and morphology according to strict criteria (\%) of normal rage (BMI 18.5 to $24.99 \mathrm{~kg} / \mathrm{m}^{2}$ ), overweight (BMI 25.0 to $29.99 \mathrm{~kg} / \mathrm{m}^{2}$ ) and obese (BMl over $30.0 \mathrm{~kg} / \mathrm{m}^{2}$ ) groups.

\begin{tabular}{|c|c|c|c|c|}
\hline \multicolumn{2}{|c|}{ Normal range $(\mathrm{n}=20)$} & $\begin{array}{l}\text { Overweight } \\
\quad(n=42)\end{array}$ & $\begin{array}{l}\text { Obese } \\
(n=14)\end{array}$ & $\mathrm{p}$ \\
\hline \multicolumn{5}{|c|}{ Concentration (million/mL) } \\
\hline Median; SD & $52.19 ; 45.75$ & $61.91 ; 61.48$ & $55.09 ; 72.48$ & 0.82 \\
\hline Min-max & $6.6-157.5$ & $0.4-226.0$ & $0.1-239.0$ & \\
\hline \multicolumn{5}{|c|}{ Total Motility (\%) } \\
\hline Median; SD & $48.03 ; 18.52$ & $52.46 ; 21.44$ & $38.79 ; 26.26$ & 0.129 \\
\hline Min-max & $7.0-75.0$ & $0.0-87.5$ & $3.5-82.5$ & \\
\hline \multicolumn{5}{|c|}{ Progressive Motility (\%) } \\
\hline Median; SD & $17.88 ; 17.02$ & $\begin{array}{l}26.61 ; \\
21.41 \S\end{array}$ & $\begin{array}{l}12.07 \\
19.23 \S\end{array}$ & 0.044 \\
\hline Min-max & $0.0-47.5$ & $0.0-70.0$ & $0.0-70.0$ & \\
\hline \multicolumn{5}{|c|}{ Strict Morphology (\%normal) } \\
\hline Median; SD & $0.95 ; 1.78$ & $1.65 ; 2.20$ & $1.50 ; 2.49$ & 0.361 \\
\hline
\end{tabular}

SD: Standard Deviation;

Min-max: Minimum-maximum

$p<0.05$

*Kruskal-Wallis test result

§Significant difference among
Table 4: Mean, Standard deviation, maximum and minimum values of hormonal parameter of total testosterone $(\mathrm{ng} / \mathrm{dL})$, free testosterone (pmol/L), prolactin $(\mathrm{mcg} / \mathrm{L}), \mathrm{FSH}(\mathrm{mUl} / \mathrm{mL}), \mathrm{LH}(\mathrm{mUl} / \mathrm{mL})$ and estradiol $\left(\mathrm{ng} / \mathrm{dL}\right.$ ) of normal rage (BMI 18.5 to $\left.24.99 \mathrm{~kg} / \mathrm{m}^{2}\right)$, overweight (BMI 25.0 to $29.99 \mathrm{~kg} / \mathrm{m}^{2}$ ) and obese (BMI over $30.0 \mathrm{~kg} / \mathrm{m}^{2}$ ) groups.

\begin{tabular}{|c|c|c|c|c|}
\hline & $\begin{array}{l}\text { Normal range } \\
\quad(n=20)\end{array}$ & $\begin{array}{l}\text { Overweight } \\
\qquad(n=42)\end{array}$ & $\begin{array}{l}\text { Obese } \\
(n=14)\end{array}$ & $p$ \\
\hline \multicolumn{5}{|c|}{ Total Testosterone (ng/dL) } \\
\hline Median; SD & $544.68 ; 209.45$ & $\begin{array}{l}490.53 \\
194.65\end{array}$ & $\begin{array}{l}441.89 \\
150.13\end{array}$ & 0.394 \\
\hline Min-max & $253.0 ; 1050.0$ & $\begin{array}{l}109.0 \\
1018.0\end{array}$ & $207.0 ; 666.0$ & \\
\hline \multicolumn{5}{|c|}{ Free Testosterone (pmol/L) } \\
\hline Median; SD & $23.74 ; 13.12$ & $38.24 ; 54.88$ & $22.32 ; 17.05$ & 0.482 \\
\hline Min-max & $1.9 ; 44.6$ & $7.3 ; 301.0$ & $4.7 ; 52.2$ & \\
\hline \multicolumn{5}{|c|}{ Prolactin (mcg/L) } \\
\hline Median; SD & $8.51 ; 2.97$ & $9.46 ; 5.69$ & $7.88 ; 3.61$ & 0.617 \\
\hline Min-max & $2.0 ; 13.0$ & $3.5 ; 28.9$ & $4.7 ; 16.0$ & \\
\hline \multicolumn{5}{|c|}{ FSH $(\mathrm{mUI} / \mathrm{L})$} \\
\hline Median; SD & $4.62 ; 1.30$ & $4.60 ; 2.60$ & $5.03 ; 2.70$ & 0.884 \\
\hline Min-max & $3.1 ; 7.3$ & $1.2 ; 12.5$ & $1.0 ; 10.2$ & \\
\hline \multicolumn{5}{|c|}{ LH (mUI/L) } \\
\hline Median; SD & $4.75 ; 1.99$ & $4.71 ; 1.92$ & $4.02 ; 1.27$ & 0.587 \\
\hline Min-max & $1.9 ; 8.2$ & $1.5 ; 8.6$ & $2.3 ; 6.3$ & \\
\hline \multicolumn{5}{|c|}{ Estradiol (ng/dL) } \\
\hline Median; SD & $12.28 ; 12.74$ & $18.21 ; 16.57$ & $17.05 ; 1735$ & 0.562 \\
\hline Min-max & $1.6 ; 42.0$ & $1.0 ; 52.6$ & $1.6 ; 44.0$ & \\
\hline
\end{tabular}

\section{Discussion}

Both obesity and male infertility are globally increasing over the last few decades (24). The impact of obesity on male fertility has been discussed in many studies however, the results are controversial. The relationship between obesity and alteration of sperm parameters on infertile men is likely multifactorial and different pathophysiological hypotheses has been raised. Firstly, alterations of the hypothalamic-pituitary-gonadal axis have been suggested to be involved in this process. Indeed, aromatization of steroids to estrogens in peripheral tissues leads to the hypogonadotropic hyper estrogenic hypogonadism previously described in obese men Schneider G, et al. [25], with a significant decrease in total and free testosterone levels and increase in estradiol levels, both leading to deleterious effects on spermatogenesis. Winters et al have also suggested that obesity may directly affect spermatogenesis and Sertoli cell function, as prescribed by the sharp decline of inhibin-B levels compared with the decrease of FSH [26]. In the present study, the authors investigated the association between BMI and serum concentrations of male sex hormones as well as semen analysis parameters. No significant statistic difference was found on hormonal parameters, thus, a significant decreased of progressive motility parameter had related in obesity man, by contrast overweight that was higher than normal range group. Corroborating our results, Chavarro JE, et al. [27] studied 483 male members of infertile couples and found no differences between health and obese male with regards the semen concentration and 
motility, although they found a lower ejaculated volume in obese man. Similarly, Jessen et al studied 1.558 Danish and had the same result among the total number of spermatozoon and motility, and the ejaculated volume as well. Nevertheless, they found a lower sperm concentration and total sperm count on lower BMI group (BMI less than $20 \mathrm{~kg} / \mathrm{m}^{2}$ ) [15].

Negative effect of obesity on sperm parameters is not consistent; there is no clear dose-response mechanism reported. Various studies have shown obesity associated with reduction in sperm count and concentration, motility, vitality, morphology, and/or DNA integrity. In contrast, other researchers have not found similar relationships [5,14]. Two meta-analytical reviews highlighted numerous opposing conclusions. Paternal obesity is also associated with reduced live birth rates following assisted reproductive technology [28]. In addition, other evidence suggests that paternal genetic health cues may be transmitted to the child, with the mediator mostly likely occurring via spermatozoa [12]. Further research on potential mechanisms associated with the impact of obesity on male reproductive health is therefore warranted, especially correlating overweight and sperm motility [29]. Regarding the lifestyle factors, the diet is strongly related to seminal pattern. It is known that saturated fatty acids were negatively related to sperm concentration and motility. This agrees with previous work showing higher saturated fatty acid concentrations in sperm of asthenozoopermic [30,31] and oligospermic males when compared with normozoospermic subjects [30]. Similarly, sperm and seminal plasma levels of omega-3 PUFAs, specifically sperm DHA and seminal plasma EPA, were positively related to sperm concentration and motility. These findings are consistent with those presented in the literature. Levels of omega-3 PUFAs in human sperm, specifically DHA, have positive correlation to sperm concentration, motility and morphology $[5,32,33]$.

\section{Sperm motility is determined by several factors}

(I) after spermatocytogenesis, testicular sperm are morphologically mature, however, in its storage in the epididymal tail, remains in the immobile state. Epididymal microenvironment is characterized by low concentrations of cAMP and calcium, important to suppress the generation of reactive oxygen species (ROS). However, the increase in intracellular calcium concentrations initiates a cascade reaction, followed by an increase ROS generation, and an increase in concentration of intracellular cAMP with subsequent development of a vigorous motility, known as hyperactivation; (II) factors such as membrane fluidity can contribute to the high complexity function involved in sperm motility. Sperm membrane is rich in polyunsaturated fatty acids and the presence of excessive seminal oxidative stress may negatively interfere in its fluidity, a process called lipid peroxidation; (III) finally, the motility of spermatozoa depends on an adequate power generation mechanism [34]. Whereas individuals with overweight and obese men have a high food consumption, including fatty acids as polyunsaturated fats (omega-3, DHA, omega- 6 and linoleic acid) [35]. We suggest that the increase of progressive sperm motility observed in overweight men may be related to this higher intake. Systemic effects of obesity in men with BMI $>25 \mathrm{~kg} / \mathrm{m} 2$, such as oxidative stress, must have overcome the potential beneficial effects of extra polyunsaturated fat acids consumption.

Semen quality parameters can be adversely affected by other environmental factors, such as stress, smoking, alcohol, medications, addiction drugs and fat dietary intake, which were not considered in this study $[8,17,36,37]$. Furthermore, we cannot disregard the relatively small sample size which might be a limiting factor of this study. On the other hand, by using solely the BMI, does not provide the exact body composition (ex.: percentage of total body fat, lean muscle mass, water, etc.). One could assume, for example, that moderate overweigh men might have a significant higher lean body mass. Therefore, the increased in progressive sperm motility could theoretically be attributed to boosting of metabolism, or some associated dietary factor such as omega-3 PUFAs intake in their diet that was not considered in this methodology.

\section{Conclusion}

In conclusion, our results indicated a relationship between overweight infertile men and an increase in an important basic semen parameter: progressive motility, further reinforcing the need for a global assessment of men's health, especially in certain subgroups of men such those who desire to father their own offspring currently or in the future.

\section{Acknowledgement}

None.

\section{Conflict of Interest}

No conflict of interest.

\section{References}

1. Flegal KM, Carroll MD, Kit BK, Ogden CL (2012) Prevalence of Obesity and Trends in the Distribution of Body Mass Index Among US Adults, 1999-2010. JAMA 307(5): 491-497.

2. Stothard KJ, Tennant PWG, Bell R, Rankin J (2009) Maternal Overweight and Obesity and the Risk of Congenital Anomalies. JAMA 301(6): 636650 .

3. IBGE. POF 2008-2009: Malnutrition falls, and Brazilian children's weight exceeds international standard (2010).

4. Heal DJ, Gosden J, Smith SL (2009) Regulatory challenges for new drugs to treat obesity and comorbid metabolic disorders. Br J Clin Pharmacol 68(6): 861-874

5. Sermondade N, Faure C, Fezeu L, Shayeb AG, Bonde JP, et al. (2013) BMI in relation to sperm count: an updated systematic review and collaborative meta-analysis. Hum Reprod Update 19(3): 221-231.

6. Mac Donald AA, Herbison GP, Showell M, Farquhar CM (2010) The impact of body mass index on semen parameters and reproductive hormones in human males: a systematic review with meta-analysis. Hum Reprod Update 16(3): 293-311.

7. Swan SH, Elkin EP (1999) Declining semen quality: can the past inform the present? Bioessays 21(7): 614-621.

8. Jouannet P, Wang C, Eustache F, Kold Jensen T, Auger J (2001) Semen quality and male reproductive health: the controversy about human sperm concentration decline. APMIS 109(5): 333-344

9. Finucane MM, Stevens GA, Cowan MJ, Danaei G, Lin JK, et al. (2011) National, regional, and global trends in body-mass index since 1980: 
systematic analysis of health examination surveys and epidemiological studies with 960 country-years and $9 \cdot 1$ million participants. Lancet 377(9765): 557-567.

10. Monteiro RA, Pariz J, Pieri P, Saldiva P, Hallak J (2012) Seminal Quality Decreases Over The 9 Years in Sao Paulo City. J Androl Supplement: 8182

11. Hallak J, Veras M, Saldiva P (2017) How environmental and air pollution disrupt spermatogenesis and male reproductive health: a mechanistic approach. In: Bioenvironmental Issues Affecting Men's Reproductive and Sexual Health, pp: 636.

12. Sallmen M, Sandler DP, Hoppin JA, Blair A, Baird DD (2006) Reduced Fertility Among Overweight and Obese Men. Epidemiology 17(5): 520523.

13. Hallak J, Andrietta J, Pieri P, Pariz J, Saldiva P (2016) Influence of air pollution ovehicular origin on seminal parameters of traffic controllers. Androl Suppl pp: 104.

14. Nguyen RHN, Wilcox AJ, Skjaerven R, Baird DD (2007) Men's body mass index and infertility. Hum Reprod 22(9): 2488-2493.

15. Jensen TK, Andersson AM, Jørgensen N, Andersen AG, Carlsen E, et al. (2004) Body mass index in relation to semen quality and reproductive hormones among 1,558 Danish men. Fertil Steril 82(4): 863-870.

16. Fariello RM, Pariz JR, Spaine DM, Gozzo FC, Pilau EJ, et al. (2012) Effect of smoking on the functional aspects of sperm and seminal plasma protein profiles in patients with varicocele. Hum Reprod 27(11): 3140-3149.

17. Pasqualotto FF, Sobreiro BP, Hallak J, Pasqualotto EB, Lucon AM (2006) Cigarette smoking is related to a decrease in semen volume in a population of fertile men. BJU Int 97(2): 324-326.

18. Paasch U, Grunewald S, Kratzsch J, Glander HJ (2010) Obesity and age affect male fertility potential. Fertil Steril 94(7):2898-2901.

19. Cocuzza M, Athayde KS, Agarwal A, Sharma R, Pagani R, et al. (2008) AgeRelated Increase of Reactive Oxygen Species in Neat Semen in Healthy Fertile Men. Urology 71(3): 490-494.

20. Aggerholm AS, Thulstrup AM, Toft G, Ramlau Hansen $\mathrm{CH}$, Bonde JP (2008) Is overweight a risk factor for reduced semen quality and altered serum sex hormone profile? Fertil Steril 90(3): 619-626.

21. World Health Organization (2010) WHO Guidelines-BMI Classification.

22. WHO (2010) World Health Organization: WHO laboratory manual for the examination and processing of human semen (5 Edn), WHO Press, Switzerland.

23. Kruger TF, Menkveld R, Stander FS, Lombard CJ, Van der Merwe JP, et al. (1986) Sperm morphologic features as a prognostic factor in in vitro fertilization. Fertil Steril 46(6): 1118-1123.

24. Palmer NO, Bakos HW, Fullston T, Lane M (2012) Impact of obesity on male fertility, sperm function and molecular composition Spermatogenesis 2(4): 253-263.
25. Schneider G, Kirschner MA, Berkowitz R, Ertel NH (1979) Increased Estrogen Production in Obese Men. J Clin Endocrinol Metab 48(4): 633638.

26. Winters SJ, Wang C, Abdelrahaman E, Hadeed V, Dyky MA, et al. (2006) Inhibin-B levels in healthy young adult men and prepubertal boys: is obesity the cause for the contemporary decline in sperm count because of fewer Sertoli cells? J Androl 27(4): 560-564.

27. Chavarro JE, Toth TL, Wright DL, Meeker JD, Hauser R (2010) Body mass index in relation to semen quality, sperm DNA integrity, and serum reproductive hormone levels among men attending an infertility clinic. Fertil Steril 93(7): 2222-2231.

28. Fariello RM, Pariz JR, Spaine DM, Cedenho AP, Bertolla RP, et al. (2012) Association between obesity and alteration of sperm DNA integrity and mitochondrial activity. BJU Int 110(6): 863-867.

29. Leisegang K, Bouic PJD, Menkveld R, Henkel RR (2014) Obesity is associated with increased seminal insulin and leptin alongside reduced fertility parameters in a controlled male cohort. Reprod Biol Endocrinol 12(1): 34

30. Aksoy Y, Aksoy H, Altınkaynak K, Aydın HR, Özkan A (2006) Sperm fatty acid composition in subfertile men. Prostaglandins Leukot Essent Fatty Acids 75(2): 75-79.

31. Tavilani H, Doosti M, Nourmohammadi I, Mahjub H, Vaisiraygani A, et al. (2007) Lipid composition of spermatozoa in normozoospermic and asthenozoospermic males. Prostaglandins, Leukot Essent Fatty Acids 77(1): 45-50

32. Tavilani H, Doosti M, Abdi K, Vaisiraygani A, Joshaghani HR (2006) Decreased polyunsaturated and increased saturated fatty acid concentration in spermatozoa from asthenozoospermic males as compared with normozoospermic males. Andrologia 38(5):173-178.

33. Safarinejad MR (2011) Effect of omega-3 polyunsaturated fatty acid supplementation on semen profile and enzymatic antioxidant capacity of seminal plasma in infertile men with idiopathic oligoasthenoteratospermia: a double-blind, placebo-controlled, randomised study. Andrologia 43(1): 38-47.

34. Piomboni P, Focarelli R, Stendardi A, Ferramosca A, Zara V (2012) The role of mitochondria in energy production for human sperm motility. Int J Androl 35(2): 109-124.

35. Attaman JA, Toth TL, Furtado J, Campos H, Hauser R, et al. (2012) Dietary fat and semen quality among men attending a fertility clinic. Hum Reprod 27(5): 1466-1474.

36. Fariello RM, Pariz JR, Spaine DM, Gozzo FC, Pilau EJ, et al. (2012) Effect of smoking on the functional aspects of sperm and seminal plasma protein profiles in patients with varicocele. Hum Reprod 27(11): 3140-3149.

37. Mendiola J, Torres Cantero AM, Moreno Grau JM, Ten J, Roca M, et al. (2019) Food intake and its relationship with semen quality: a casecontrol study. Fertil Steril 91(3): 812-818. 